\title{
Desenvolvimentismo e inclusão política: tensões ou sinergias na implementação de grandes projetos de infraestrutura?
}

Roberto Rocha C. Pires*

\section{Resumo}

Na última década, observou-se, no Brasil, a retomada de grandes projetos de infraestrutura, típicos do período nacional-desenvolvimentista, com relevantes impactos socioambientais e envolvendo consideráveis conflitos. 0 presente artigo se dedica a investigar como se dá essa retomada no contexto institucional pós-1988, concentrando-se nos efeitos da inclusão de atores políticos e da participação social sobre a implementação de duas dessas iniciativas governamentais: o projeto de transposição do Rio São Francisco e a construção da Usina Hidrelétrica de Belo Monte. Enquanto, no primeiro caso, verificou-se a presença e operação de múltiplas arenas de inclusão e negociação política (como o Congresso Nacional e mecanismos de participação social), no segundo, as oportunidades de articulação com atores políticos e sociais foram muito mais restritas. A análise comparativa indicou que tais variações no grau de inclusão e participação contribuem para explicar por que, no primeiro caso, observaramse repactuações e inovações (sinergias) e, no segundo caso, a reprodução de conflitos e obstáculos (tensões) na implementação dos projetos.

\section{Palavras-chave}

Implementação. Participação. Burocracia.

\begin{abstract}
In the last decade, the federal government, in Brazil, restarted the implementation of large infrastructure projects, those typical of the national-developmentalist period, with relevant social and environmental impacts, involving significant political conflicts. This article investigates the implementation of such projects in the current institutional context
\end{abstract}

\footnotetext{
* Doutor em Políticas Públicas pelo Massachusetts Institute of Technology (MIT); pesquisador do Instituto de Pesquisa Econômica Aplicada (IPEA), atuando na Diretoria de Estudos sobre Estado, Instituições e Democracia (Diest) em Brasília, Distrito Federal - Brasil. Email: roberto.pires@ipea.gov.br.
} 
(post-1988 Constitution). It focuses on the effects of political inclusion (Congress and public participation) on two emblematic projects: the transposition of the São Francisco River and the construction of the Belo Monte Dam. While in the first case, we observed the operation of multiple arenas for political participation and negotiation, in the second case, opportunities for interest articulation with political and social actors were scarce. Findings from comparative analysis indicate that such variation on political inclusion and participation contribute to explain why, in the first case, we observed new agreements and innovations (synergies) and, in the second case, the reproduction of conflicts and obstacles to implementation (tensions).

\section{Keywords}

Implementation. Participation. Bureaucracy.

\section{Introdução ${ }^{1}$}

Os anos 2000 marcaram a retomada de um ativismo estatal na produção de políticas de desenvolvimento pelo governo federal brasileiro. Foram lançadas (ou reforçadas) iniciativas importantes, como as políticas de desenvolvimento industrial e as políticas de investimento e desenvolvimento de infraestrutura. Tais políticas têm se caracterizado pela definição de objetivos ambiciosos de transformação das estruturas produtivas nacionais e marcadas pelos imperativos da urgência na sua implementação e da rapidez na entrega dos resultados. O exemplo mais visível disso é o Programa de Aceleração do Crescimento (PAC I e II), o qual toma como objetivos ativar a demanda, gerar empregos e superar a situação de baixo crescimento econômico do país, por meio do aumento de investimentos públicos em infraestrutura e estímulos para outros setores econômicos. Além de ser tratado como prioridade central pelo governo federal e de sua envergadura orçamentária, como o próprio nome já indica, o PAC define-se pela necessidade de acelerar o crescimento,

\footnotetext{
1 O autor gostaria de agradecer aos pareceristas de Interseções - Revista de Estudos Interdisciplinares, além de Ronaldo Coutinho Garcia, Ana Karine Pereira e a Rebecca Abers, pelos valiosos comentários e sugestões de revisão, os quais contribuíram muito para o aperfeiçoamento do texto e seus argumentos. Erros, omissões e imprecisões são de inteira responsabilidade do autor.
} 
por meio da urgência na implementação de ações que sejam capazes de, rapidamente, produzirem impactos.

Essas características observadas nas políticas contemporâneas forçam sua aproximação às políticas desenvolvimentistas dos anos 1960-70, concebidas e implementadas em um ambiente político autoritário. Naquele contexto, a atuação estatal era caracterizada pelo insulamento tecnoburocrático (MARTINS, 1985) e pela tomada de decisões em arenas restritas, sem a participação de atores sociais e com envolvimento limitado e seletivo de atores políticos e econômicos ${ }^{2}$. Essas condições permitiram aos governos militares produzirem políticas de desenvolvimento com rapidez decisória e executiva, uma vez que eram reduzidas as oportunidades de participação, expressão de conflitos e negociação ${ }^{3}$.

Situação bastante diferente caracteriza o ambiente político-institucional brasileiro pós-1988. A Constituição vigente restaurou o Estado Democrático de Direito, restabeleceu as eleições periódicas, a independência dos Poderes da República (conferindo autonomia relativa aos Poderes Legislativo e Judiciário), além de ter instituído mecanismos para o envolvimento de atores políticos, econômicos e sociais no processo de formulação de políticas públicas, por meio da ampliação de instrumentos de controle, participação e transparência na gestão pública. Nesse ambiente comparativamente mais complexo, as burocracias do Executivo precisam lidar simultaneamente com agentes políticos (lideranças partidárias, parlamentares, governadores e prefeitos, entre outros), processos participativos (conselhos, conferências, audiências e consultas públicas, ouvidorias, entre outros) e controles burocráticos (órgãos de controle interno e externo, incluindo-se o Ministério Público) (SÁ e SILVA; LOPES; PIRES, 2010; GOMIDE; PIRES, 2014). Além disso, a Constituição e a legislação posterior introduziram novos direitos e

\footnotetext{
${ }^{2}$ Nesse sentido, cabe recordar a noção de "anéis burocráticos", por meio da qual Cardoso (1975) procurou descrever as relações entre funcionários públicos, empresários, militares e detentores de cargos políticos em torno da definição de políticas públicas no regime autoritário. Tais anéis se definiam pela formação de "círculos de interessados" de maneira informal ou não necessariamente pública, de forma distanciada de qualquer tipo de legitimação das políticas públicas a partir da "sociedade civil" e dos representantes políticos eleitos para o Congresso Nacional.

${ }^{3}$ Entre os anos de 1950 e 70, foi produzida uma média de 98 grandes barragens por década no Brasil (HOCHSTETLER, 2011).
} 
garantias individuais e coletivas, como a proteção de minorias étnico-raciais e do meio ambiente ${ }^{4}$.

Assim, a retomada de políticas com traços desenvolvimentistas em um ambiente marcado pela ampliação da inclusão política nos instiga a questionar as implicações desse encontro entre ativismo burocrático e instituições democráticas. A questão que orienta a presente análise diz respeito aos efeitos da vigência de instituições democráticas (i.e. ampliação da inclusão política via interações com o Congresso Nacional e oportunidades de participação social) sobre as políticas de desenvolvimento. Basicamente, busca-se compreender em que medida a formação de arranjos decisórios com maior abertura e inclusão de uma pluralidade de atores afeta (positiva ou negativamente, e como) a implementação das políticas. Por abertura ou inclusão política, compreende-se as possibilidades de exposição e interação das burocracias do Poder Executivo encarregadas da implementação de políticas públicas, por um lado, com os agentes políticos (Congresso Nacional, partidos políticos, governadores, prefeitos, etc.) e atores da sociedade civil (movimentos sociais, sindicatos, associações, ONGs, etc.), por outro ${ }^{5}$.

Para tal, o presente estudo se baseia em uma análise comparativa de casos que podem ser considerados emblemáticos da retomada recente de um estilo desenvolvimentista de atuação estatal: o Projeto de Transposição das Águas do Rio São Francisco (PTSF) e a implantação da Usina Hidrelétrica de Belo Monte (UHBM). A seleção dos casos se justifica pela importância e visibilidade que eles têm tido nos debates políticos recentes, nas discussões

\footnotetext{
${ }^{4}$ Desde 1980, reformas na legislação ambiental vêm estabelecendo exigências para a realização de projetos de infraestrutura com impacto socioambiental, além de instituir um sistema de governança de múltiplos níveis e com a participação de diversos atores com poder de veto. Nesse processo de reforma, destaca-se a criação do Sistema Nacional do Meio Ambiente, a atuação do Conselho Nacional do Meio Ambiente (Conama) e a operacionalização e definição de critérios para os Estudos de Impacto Ambiental. Além disso, chama-se atenção também para o capítulo sobre meio ambiente na Constituição de 1988 e para a Lei de Ação Civil Pública, a qual empodera o Ministério Público para agir em nome da sociedade nesse tipo de questão.

${ }^{5}$ Ao chamar a atenção, simultaneamente, para as interações com agentes políticos e atores sociais, o presente trabalho inova em relação à grande parte dos estudos sobre políticas públicas no Brasil, os quais tendem a privilegiar análises focadas e um ou outro tipo de ator/interação. Reconhecendo que, tanto as interações agentes políticos (lideranças partidárias, parlamentares, governadores e prefeitos, etc.) quanto os processos participativos (conselhos, conferências, audiências e consultas públicas, ouvidorias, etc.) são traços característicos do ambiente políticoinstitucional brasileiro e moldam a produção de políticas públicas, a presente análise busca contemplar ambas dimensões.
} 
acadêmicas sobre a retomada de um ativismo estatal, e por apresentarem uma série de semelhanças no que tange a suas trajetórias, objetivos e impactos, permitindo sua análise comparativa. Ambos são grandes projetos de infraestrutura, envolvendo conflitos e relevantes impactos socioambientais, concebidos originalmente no regime militar, sob a influência do nacionaldesenvolvimentismo, e retomados como prioridades governamentais na década passada a partir da sua inclusão no PAC. No entanto, apesar dessas (e outras) semelhanças, os casos diferem marcadamente no que diz respeito à inclusão e à participação de atores políticos e sociais. Enquanto, no primeiro, as arenas são diversificadas e inclusivas, no segundo, são escassas, seletivas e precariamente conduzidas. Assim, a comparação nos permitirá compreender como a variação em termos de inclusão política condiciona a implementação das políticas públicas em questão.

$\mathrm{O}$ artigo encontra-se organizado da seguinte forma. Na próxima seção, revemos o debate na literatura sobre desenvolvimentismo e inclusão política, identificando os argumentos sobre a relação entre políticas desenvolvimentistas e instituições democráticas. Na sequência, as políticas analisadas são descritas e comparadas: primeiramente, quanto aos seus elementos comuns; em seguida, quanto às diferenças em termos de inclusão política; e, por fim, quanto aos efeitos observados sobre a implementação das políticas. Na seção final (conclusão), argumentamos que a comparação empreendida sugere que a ampliação da inclusão política, apesar de introduzir complexidades na gestão das políticas, cria oportunidades para o aprimoramento, revisões e inovações na ação governamental; ao passo que sua ausência (ou limitação) prejudica a explicitação e o processamento de conflitos, podendo levar ao aumento de obstáculos para a implementação das políticas públicas.

\section{Políticas desenvolvimentistas e inclusão política: tensões ou sinergias?}

A retomada de políticas com traços tipicamente desenvolvimentistas em um contexto político-institucional que institui requerimentos voltados para a inclusão e participação de atores políticos e sociais diversos poderia resultar tanto em tensões, impasses e ineficiências, por um lado, quanto em sinergias, aprimoramentos e inovações, por outro. A literatura internacional, que 
tem se dedicado a avaliar as relações entre a implementação de políticas desenvolvimentistas e instituições democráticas, reforça a percepção de tais posições divergentes e também do caráter aberto do debate.

De um lado, autores como Johnson (1982), Leftwich (1998) e Wade (1990) argumentam no sentido de uma incongruência (ou trade-off) entre a implementação de políticas desenvolvimentistas, as quais requerem burocracias fortes e insuladas, e a vigência de instituições democráticas. Essa visão alicerça-se na percepção de que a democracia, ao proporcionar a inclusão política de um conjunto variado de atores, tende a constituir um sistema de poder conservador, bloqueando transformações rápidas, pois envolve sequências de acomodação de interesses entre elites políticas, impondo restrições às políticas do tipo "big push". Além disso, a inclusão de novos atores e a ampliação dos interesses envolvidos nos processos decisórios provocariam um excesso de demandas sobre o sistema político, elevando expectativas, reduzindo as possibilidades de consenso e, por isso, minando as capacidades de realização de objetivos em ritmo acelerado. Os estudos que se dedicaram a analisar as experiências de Estados desenvolvimentistas do Leste Asiático corroboram essas percepções. Ao se debruçarem sobre países com sistemas políticos não democráticos e pouco abertos às representações de atores sociais e políticos (por exemplo, Coreia do Sul, Taiwan, Indonésia e, mais recentemente, a China), chamaram atenção para a autonomia das burocracias estatais na definição e condução das políticas estratégicas para o desenvolvimento. Tal como assinala Chalmers Johnson:

“(...) a operação efetiva do Estado desenvolvimentista requer que a burocracia que dirige o desenvolvimento econômico esteja protegida de todos os grupos de interesse - e dos mais poderosos a fim de que ela possa definir e alcançar prioridades industriais de longo prazo. Um sistema no qual os grupos de interesse existentes em uma sociedade moderna e aberta exercem uma ampla pressão sobre o governo certamente não alcançará o desenvolvimento econômico, ao menos sob a égide do governo, independente dos demais valores que este possa concretizar. O sucesso de uma burocracia econômica em preservar mais ou menos intacta a sua influência preexistente foi, portanto, pré-requisito para o sucesso das políticas industriais dos anos 50" (JOHNSON, 1982, p.44 Tradução livre).

As interpretações de alguns autores do campo de estudos sobre implementação de políticas públicas também reforçam essas conclusões. Por 
exemplo, em seu estudo pioneiro sobre o programa de fomento ao emprego de minorias nos Estados Unidos, Pressman e Wildavsky (1973) revelaram de forma detalhada as complexidades dos processos de implementação envolvendo diversos atores em múltiplos níveis (de congressistas no nível nacional a funcionários de linha de frente no governo local) - e seus efeitos perversos para a consecução dos resultados projetados pelos formuladores do programa. Na mesma linha, Bardach (1977) desenvolveu a abordagem dos "jogos de implementação" e demonstrou que, quanto maior o número de atores e arenas decisórias envolvidas nos processos de implementação, menores são as chances de sucesso.

Por outro lado, diversos outros autores questionam a existência de incongruências entre a promoção de políticas de desenvolvimento arrojadas e transformadoras e a ampliação da participação por parte de atores políticos e sociais. Advogam, até mesmo, que tais elementos atuam em sinergia para a produção de ações governamentais mais responsivas e efetivas. Nessa linha, a ampliação da participação política na tomada de decisões tem sido compreendida não apenas como elemento central do processo, mas também como do próprio conteúdo de uma renovada noção de desenvolvimento (SEN, 2000).

Para Evans (2011; 2013), a participação de atores sociais e agentes políticos, ao contrário de emperrar as políticas desenvolvimento, aumentar seus custos de transação e comprometer sua efetividade, pode torná-las ainda mais funcionais à medida que debates entre diferentes perspectivas poderiam levar a reformulações conceituais e práticas capazes de aperfeiçoar políticas públicas. Assim, segundo o autor, "os laços Estado-sociedade constituem o cerne do problema na construção de um Estado desenvolvimentista no século XXI" (2011, p.10 - Tradução livre). Isso porque as interações entre burocracias executoras e atores políticos e sociais (a) ampliam o acesso à informação e conhecimento sobre os problemas a serem enfrentados e (b) criam oportunidades para estratégias mais eficientes e efetivas de "coprodução" de políticas públicas, por meio do compartilhamento de recursos, parcerias e apoio político, institucional ou administrativo (ABERS; KECK, 2013; EVANS, 2013).

Outros autores têm argumentado que a inclusão de uma pluralidade de atores políticos nos processos decisórios contribui não apenas para a qualidade das decisões, como também para a legitimidade das políticas públicas. O estudo de Lipjhart (1999), o qual confrontou empiricamente o desempenho das democracias de tipo majoritária - mais concentradoras 
do poder no Executivo - com os arranjos institucionais do tipo consociativo - nos quais o poder de decisão está mais fragmentado - indica que não há comprovação de que a redução do número de atores influentes nos processos decisórios leve a decisões de qualidade superior, nem tampouco que a rapidez do processo decisório gere, necessariamente, melhores resultados nas políticas governamentais. Segundo o autor:

Políticas apoiadas em amplos consensos são mais propensas de serem implementadas com maior sucesso e a seguir seu curso do que políticas impostas por um governo que toma decisões contrárias aos desejos de importantes setores da sociedade. (LIJPHART,1999, p.260. Tradução livre).

Por sua vez, Stark e Brustz (1998) sugerem que o sucesso da implementação de uma política pública vai depender da sua estabilidade e coerência interna, as quais seriam aumentadas por estruturas institucionais que exijam amplas negociações e debate entre uma pluralidade de atores políticos envolvidos. A partir da análise da formulação e implementação de políticas econômicas em três democracias no Leste Europeu após o socialismo, os autores observam que a coerência e a qualidade das políticas aumentam quando as burocracias do Poder Executivo têm que dialogar e prestar contas de suas decisões às diversas forças políticas no Parlamento e na sociedade organizada. Tendo que negociar suas propostas com outros atores, os policymakers aumentam a compreensão dos problemas, ampliam sua capacidade de obter informações críticas, corrigindo erros de cálculo que, na ausência desse processo, só apareceriam no momento da execução. Neste sentido, os processos decisórios inclusivos possibilitam resultados mais eficientes do que aqueles originários de arenas insuladas e de poder concentrado, porque aumentam a informação tanto do ponto de vista técnico (soluções alternativas podem emergir) como do ponto de vista da manifestação das diversidades de preferências e soluções políticas sobre o tema em questão (LOUREIRO; MACÁRIO; GUERRA, 2013).

Os debates em torno da noção de governança também têm abordado a problemática em tela, chamando atenção para o fato de que novas formas organizacionais emergentes, envolvendo articulações entre atores estatais e não estatais, contribuem para a construção de novas capacidades para a produção de políticas públicas. Isto é, as articulações entre burocracias, atores políticos e sociais podem promover maior capilaridade da ação estatal, combinação de recursos diversos, monitoramento intensivo e multifocal, 
além de oferecer oportunidades para o aprendizado e a inovação a partir de reflexões coletivas (MATTHEWS, 2012). As interações, institucionalmente articuladas, entre um conjunto diversificado de atores nos processos de implementação têm sido enfatizadas nesses debates como elementos essenciais para o melhor conhecimento sobre os problemas e para o desenho criativo de soluções para enfrentá-los (SORENSEN, 2012; SABEL; ZEITLIN, 2012). Para Sabel (2004), processos de gestão de políticas públicas mais inclusivos criam oportunidades para atores "locais" avaliarem e revisarem processos de implementação, contribuindo para uma melhor adaptação dos objetivos gerais de uma política aos contextos específicos e condições locais de execução. Tal como definido pelo autor, essa dinâmica contribui para o "aprendizado por meio do monitoramento" e, assim, para a emergência de inovações que podem contribuir para a efetividade da ação estatal.

Finalmente, estudos recentes sobre participação social no Brasil têm chamado atenção para a questão da sua efetividade sobre os processos de produção de políticas públicas (PIRES, 2011). Algumas análises têm apresentado evidências de que a existência e operação de canais de participação social trazem potenciais positivos para a melhoria do desempenho de governos e suas políticas. Por exemplo, Zamboni (2007) comparou municípios com e sem OP (Orçamento Participativo) e examinou variáveis ligadas à corrupção na administração pública, concluindo que os municípios com OP foram aqueles que, em sua maioria, tiveram menos indícios de práticas graves de corrupção. Já em Pires e Tomás (2007) e Pires e Vaz (2010), os autores compararam municípios - semelhantes em termos de tamanho populacional, renda per capita, níveis de associativismo, entre outras variáveis - que diferiam em termos do conjunto de instituições participativas existentes, incluindo OP, conselhos e outros processos participativos locais. Nesses estudos, percebeu-se que os municípios com um conjunto ativo e mais desenvolvido de instituições participativas apresentavam resultados sistematicamente melhores do que seus pares com estrutura participativa deficiente, no que diz respeito ao gasto e à oferta de serviços públicos nas áreas de saúde, educação e assistência social ${ }^{6}$.

\footnotetext{
${ }^{6}$ Outro exemplo concreto desses argumentos pôde ser observado em um estudo sobre a ampliação da participação da sociedade civil nos programas do Departamento de Transportes nos Estados Unidos. Nesse caso, Neshkova e Guo (2011) observaram que "as agências públicas podem se tornar mais eficientes e eficazes por meio da abertura dos seus processos decisórios ao público, tirando vantagem do conhecimento contextual e dos conselhos práticos que essa abertura tem a oferecer" (p. 285. Tradução livre).
} 
Assim, o corrente debate oferece duas direções possíveis para a interpretação das relações entre o ativismo das burocracias estatais na realização de políticas de desenvolvimento e a inclusão de atores sociais e políticos nos processos de implementação: a) a ampliação da participação de atores sociais e políticos tende a provocar ineficiências e impasses, impondo obstáculos à implementação; e b) a inclusão de atores sociais e políticos tende a promover maior responsividade, decisões de melhor qualidade e inovações, facilitando a implementação de políticas de desenvolvimento. A seção seguinte contrapõe esses argumentos teóricos com experiências concretas de políticas de desenvolvimento, buscando compreender os possíveis efeitos e implicações que a ampliação da inclusão política e da participação social tem provocado sobre a implementação de políticas públicas no Brasil.

\section{Grandes projetos de infraestrutura, conflitos de interesses e diferentes oportunidades de inclusão política}

A comparação entre os projetos de transposição das águas do Rio São Francisco e de construção da Hidrelétrica de Belo Monte oferece uma oportunidade interessante para se testar e qualificar os argumentos gerais apresentados pela literatura sobre os efeitos da ampliação da inclusão política na produção de políticas de desenvolvimento. Se, por um lado, essas políticas apresentam diversas características comuns, viabilizando a sua análise pareada, por outro lado, diferem essencialmente no que diz respeito a seu grau de porosidade às interferências de agentes políticos e à participação de atores sociais. Assim, a comparação proposta nos permite avaliar de que forma a inclusão de uma pluralidade de atores afeta a condução das políticas. Nesta seção, descreveremos essas semelhanças e diferenças, assim como analisaremos suas implicações para a implementação dessas políticas. As análises a seguir tomam como fonte principal dois estudos de caso que se voltaram para as políticas em questão, elaborados por Loureiro, Teixeira e Ferreira (2013), no caso do projeto de transposição das águas do Rio São Francisco (PTSF), e por Pereira (2013), no caso da construção da Hidrelétrica de Belo Monte (UHBM). Os dois estudos de caso compartilham as mesmas questões de pesquisa, métodos de coleta de dados e estratégias de análise dos arranjos institucionais de implementação, com o mapeamento das interações de atores burocráticos com atores sociais e agentes políticos, proporcionando, 
assim, um nível mínimo de padronização entre as abordagens e equilíbrio para a comparação ${ }^{7}$. Acrescentam-se, ainda, de forma subsidiária, análises recentes produzidas por outros autores sobre os casos em estudo.

\section{a) Elementos comuns}

Os projetos de transposição das águas do Rio São Francisco (PTSF) e de construção da Usina Hidrelétrica de Belo Monte (UHBM) têm diversas características em comum. Ambos são grandes projetos de infraestrutura com fortes impactos socioambientais, envolvendo elevado grau de conflito e polêmicas sobre sua desejabilidade e formas de viabilização.

Nos dois casos, os projetos apresentam trajetórias semelhantes, sendo inicialmente concebidos durante o regime militar e retomados em meados dos anos 2000, quando passam a integrar a carteira de projetos do PAC, além de envolverem significativas disputas em torno dos seus objetivos. O projeto da Usina Hidrelétrica de Belo Monte foi pensado inicialmente durante a ditadura militar, período em que foi construída a maioria das hidroelétricas existentes no país. Posteriormente abandonado por vários anos, ações no sentido da retomada do projeto só vieram a ocorrer no primeiro mandato do ex-presidente Lula ${ }^{8}$, passando a integrar o PAC em 2007. Nessa retomada, o projeto passou a ser entendido como estratégico para o desenvolvimento industrial e para a manutenção do crescimento econômico do país. Desde a sua concepção inicial, o projeto é marcado por conflitos entre duas coalizões, sendo uma a que defende a solução hidroelétrica para a expansão da oferta de energia (envolvendo as burocracias e empresas estatais do setor elétrico e atores privados dos setores industriais e da construção pesada), e outra a que critica o modelo de desenvolvimento vigente e enfatiza os riscos de degradação socioambiental e de violação dos direitos de populações locais atingidas (envolvendo as burocracias do setor ambiental, o Ministério

\footnotetext{
${ }^{7}$ A elaboração de ambos estudos de caso foi parte de um projeto de pesquisa coordenado pelo Instituto de Pesquisa Econômica Aplicada (IPEA), intitulado "Estado, Democracia e Desenvolvimento no Brasil Contemporâneo", coordenado pelos pesquisadores Roberto Pires e Alexandre Gomide.

${ }^{8}$ Apesar de a retomada efetiva só acontecer a partir de 2003, o projeto de construção da hidrelétrica já havia reaparecido no planejamento governamental ainda no final do governo Fernando Henrique Cardoso, com sua inclusão no Plano Avança Brasil.
} 
Público e redes de atores da sociedade civil local, nacional e internacional) (PEREIRA, 2013; HOCHSTETLER. 2011).

O Projeto de Transposição do Rio São Francisco também apresenta uma longa história. Foi concebido no governo do Presidente João Figueiredo (1979-85), abandonado e, posteriormente, reiniciado em 2007, após uma primeira tentativa frustrada de retomada em 2003. O objetivo do projeto é combater a escassez de água no Nordeste Setentrional brasileiro e os efeitos das longas estiagens sobre os milhares de residentes na região, garantindo água para o desenvolvimento socioeconômico da região. A obra prevê a construção de mais de 600 quilômetros de canais de concreto em dois grandes eixos (norte e leste) para o desvio das águas do rio, ao longo do território de quatro estados (Pernambuco, Paraíba, Ceará e Rio Grande do Norte). Preveem-se, também, a construção de 40km de túneis, 35 reservatórios, 27 aquedutos, 9 estações de bombeamento de água e 2 centrais hidrelétricas, totalizando montante superior a $\mathrm{R} \$ 4,5$ bilhões em investimentos. A iniciativa sempre envolveu polêmica, pois alguns estados se consideravam potenciais prejudicados pela perda de recursos hídricos decorrentes da transposição (Minas Gerais, Bahia, Sergipe e Alagoas), e organizações ambientalistas e de direitos humanos, além de organizações civis locais, se preocupavam com os impactos socioambientais das obras (LOUREIRO; TEIXEIRA; FERREIRA, 2013; BRASIL, 2011).

Tanto no caso do PTSF quanto da UHBM, o aparato burocráticoadministrativo mobilizado para a implementação apresenta características semelhantes, envolvendo ministérios setoriais, empresas estatais, agências reguladoras e órgãos da Presidência da República, como a Casa Civil, responsável pela coordenação política do processo. No caso do PTSF, o núcleo burocrático reside no Ministério da Integração Nacional (MIN), encarregado da coordenação e gestão do projeto, da contratação de empresas para a execução dos projetos de engenharia e das obras necessárias, tendo como órgãos vinculados o Departamento Nacional de Obras Contra as Secas (DNOCS) e a Companhia de Desenvolvimento dos Vales do São Francisco e do Parnaíba (CODEVASF). Nessa tarefa, o MIN se relaciona com órgãos reguladores, como a Agência Nacional de Águas (ANA) e o Conselho Nacional de Recursos Hídricos (CNRH), responsáveis por expedir licenças e aprovações necessárias à implantação do projeto (LOUREIRO; TEIXEIRA; FERREIRA, 2013).

No caso da UHBM, o núcleo decisório compreende as burocracias do setor elétrico - órgãos vinculados ao Ministério de Minas e Energia (MME), 
como a Agência Nacional de Energia Elétrica (ANEEL) e as estatais do grupo Eletrobrás. Além desses órgãos vinculados ao MME, o Conselho Nacional de Política Energética (CNPE), vinculado à Presidência da República, também tem papel estratégico na proposição de políticas nacionais na área energética e aprovação de resoluções referentes à construção da Usina. Assim, esses são os atores que têm definido as principais características do projeto, como sua localização, seu tamanho e a potência da usina. A execução da obra, no caso de Belo Monte, fica a cargo do grupo Norte Energia, formado por empresas estatais e privadas do setor elétrico, entre elas a Eletrobrás, vencedor do leilão ocorrido em 2010 (PEREIRA, 2013).

Em ambos os casos, estão presentes também as burocracias do setor ambiental, como o Ministério do Meio Ambiente (MMA), o Instituto Brasileiro do Meio Ambiente e dos Recursos Naturais Renováveis (Ibama) e o Instituto Chico Mendes da Biodiversidade (ICMBio), as quais, durante as diferentes fases do processo de licenciamento ambiental do empreendimento, mobilizam também outros órgãos envolvidos com regulação e garantia de direitos, como a Fundação Nacional do Índio (Funai), Fundação Palmares, o Instituto do Patrimônio Histórico e Artístico Nacional (IPHAN), e o Instituto Nacional de Colonização e Reforma Agrária (INCRA), entre outros. Durante o licenciamento, devem ser conduzidos estudos e avaliações técnicas sobre a viabilidade e os impactos socioambientais dos empreendimentos, assim como também sobre os planos, ações e investimentos para mitigação ou compensação dos mesmos. Além disso, por força da legislação vigente, o conteúdo dessas análises e avaliações (Relatório de Impacto Ambiental) deve ser exposto aos interessados, por meio de audiências públicas, envolvendo múltiplos atores da sociedade civil, recolhendo dúvidas, críticas e sugestões sobre o empreendimento. É com base nos documentos formais e nos debates ocorridos nas audiências públicas que o órgão ambiental elabora seu parecer final sobre a viabilidade ambiental do projeto (FONSECA et al., 2013).

O processo de licenciamento socioambiental constitui uma inovação institucional importante que se consolida a partir da redemocratização, em contraposição às limitadas exigências que se impunham à realização de grandes obras no passado ${ }^{9}$, permitindo que as decisões sobre projetos de

\footnotetext{
${ }^{9}$ Por exemplo, na construção da hidrelétrica de Tucuruí, nos anos 1970, sob a vigência de uma legislação ambiental muito menos rígida, os estudos de impacto ambiental somente foram iniciados três anos após o início das obras, indicando a sua irrelevância como aspecto condicionante ao empreendimento (PEREIRA, 2013).
} 
infraestrutura sejam submetidas a avaliações por um conjunto variado de atores - os quais podem se organizar em coalizões de bloqueio ou apoio, tal como sugerido por Hochstetler e Keck (2007). Se, por um lado, o licenciamento socioambiental tornou a viabilização dos empreendimentos mais complexa, exigente e onerosa, introduzindo considerações relativas à garantia de direitos sociais, ambientais e culturais, por outro lado, sua capacidade de impor vetos ou provocar revisões substantivas em projetos com fortes impactos socioambientais tem se mostrado limitada (FEARNSIDE; LAURANCE, 2012) ${ }^{10}$.

\section{b) Diferenças em termos de inclusão política}

Apesar das semelhanças listadas, comparativamente, os dois projetos apresentam diferenças importantes no que diz respeito às oportunidades de inclusão de atores nos debates sobre os rumos das iniciativas e aos canais de participação nos processos decisórios. Se, por um lado, o PTSF tem sua implementação marcada por arenas decisórias que buscaram incluir uma pluralidade de atores estatais, políticos e societários; por outro lado, a UHBM tem sua implementação marcada pelo insulamento do núcleo decisório central e pela fragilidade dos processos de consulta à população empreendidos. Em ambos os casos, é importante destacar, os processos de consulta, negociação e tomada de decisão compartilhada têm sido criticados, principalmente, pelos atores sociais afetados e envolvidos. Quando comparados com os mecanismos disponíveis para inclusão política existentes em outras áreas de política pública, como, por exemplo, a área de políticas sociais, percebe-se a sua incipiência e limitada extensão. No entanto, embora ambos apresentem debilidades, destacam-se aqui diferenças importantes na forma como se processou a inclusão política em cada caso.

No caso do PTSF, estão presentes processos e arenas variadas que permitiram a inclusão de atores e debates sobre as características e estratégias de viabilização do projeto. Primeiramente, o projeto foi alvo de intensas negociações entre parlamentares e governadores de estados a favor

\footnotetext{
${ }^{10}$ Os autores destacam a influência do lobby dos investidores, o excessivo formalismo nos processos, a existência de viés nos estudos de impacto ambiental formulados pelos próprios empreendedores e a incapacidade de avaliação do "efeito arrasto" como limitadores da influência dos processos de licenciamento ambiental no Brasil.
} 
(receptores das águas) e contra (doadores de águas), em distintos momentos e espaços no Congresso Nacional. Na fase de licenciamento ambiental, o PTSF foi submetido a audiências públicas nas regiões afetadas, permitindo manifestações de grupos da sociedade civil local. Ao longo do processo, cabe destacar o papel desempenhado pelo Comitê de Bacia Hidrográfica do Rio São Francisco (CBHSF), vinculado ao Conselho Nacional dos Recursos Hídricos (CNRH), espaços institucionalizados de participação social nos níveis local/regional e federal, compostos por representantes da sociedade civil e do governo (LOUREIRO; TEIXEIRA; FERREIRA, 2013).

Situação diferente tem marcado a implementação da construção da UHBM. As arenas de discussão e negociação do projeto não são apenas menos variadas como também menos inclusivas e institucionalizadas. Ainda que a Constituição de 1988 tenha atribuído ao Congresso Nacional a prerrogativa de autorizar a exploração de recursos hídricos em terras indígenas, mediante consulta direta a essas populações, a aprovação legislativa do projeto tramitou pela Câmara e pelo Senado Federal em regime de urgência, em menos de um mês, no ano de 2005. A pressa e a velocidade atribuídas e esse processo impediram que fossem realizadas as oitivas das comunidades indígenas, requeridas pela legislação vigente ${ }^{11}$. As audiências públicas, posteriormente conduzidas ao longo do processo de licenciamento, apresentaram diversas falhas que limitaram sua efetividade ${ }^{12}$. Em 2009, em resposta a uma Ação Civil Pública impetrada pelo Ministério Público Federal (MPF), a FUNAI conduziu

\footnotetext{
${ }^{11}$ A aprovação de Belo Monte em tempo recorde é explicitada na fala do senador Luiz Otávio (PMDB-PA) na sessão do Senado federal que aprovou o Decreto no 788 de 2005: "A única observação que quero acrescentar no meu aparte é a seguinte: estou na Casa há mais de sete anos, e há projetos que estão aqui desde que cheguei e não saem das comissões, não andam. São projetos de vários para não dizer de todos os senadores. E esse projeto, por incrível que pareça, foi apresentado no dia 8 de julho, na semana passada. Faz quatro dias que esse projeto foi aprovado na Câmara e vamos aprová-lo aqui no Senado hoje. Eu nunca vi isso! Manifesto apenas minha admiração... Eu queria encaminhar desde a oportunidade que tive de encaminhar a urgência, mas queria saber o motivo de tanta urgência. Isso não bate!... Essa história de que Belo Monte vai resolver o problema do apagão... Essa obra é para dez anos, como disse o Presidente José Sarney, ou para quinze ou vinte anos. Então, o motivo não é o apagão" (PEREIRA, 2013, p.32).

12 Ao longo desse processo, o Ibama conduziu apenas quatro audiências públicas, em 2009, nas cidades de Altamira, Vitória do Xingu, Belém e Brasil Novo, as quais tiveram baixa participação das comunidades afetadas, dadas as distâncias entre as comunidades e os locais das reuniões e as dificuldades de acesso e locomoção na região (HOCHSTETLER, 2011; ABERS; OLIVEIRA; PEREIRA, 2014).
} 
reuniões informativas em doze comunidades indígenas, as quais, da mesma forma, ainda seguiram sendo criticadas pelo MPF e pelos grupos sociais envolvidos, por não terem criado oportunidades adequadas de discussão e inclusão dos atores afetados. Tais reuniões foram questionadas por não terem propiciado a escuta das demandas e propostas de revisão no projeto, tal como definido pela Constituição Federal de 1988 e a Convenção 169 da Organização Internacional do Trabalho. Em função dessas características, o processo decisório e de implantação da usina tem sido percebido como pouco participativo pelos atores sociais envolvidos, assim como também pelo Ministério Público, o qual, até o presente, impetrou mais de duas dezenas de ações judiciais requerendo a paralisação da obra e questionando os processos de consulta às populações afetadas, muitas dos quais aceitos pelos tribunais de primeira instância e, posteriormente, revistos pelos tribunais superiores (PEREIRA, 2013; HOCHSTETLER, 2011).

\section{c) Efeitos e implicações da inclusão política sobre a implementação}

Após a descrição dos elementos comuns (trajetórias e aparato burocráticoadministrativo) e das diferenças em termos de oportunidades para inclusão política, busca-se analisar de que forma essas variações condicionam os processos de implementação das políticas estudadas ${ }^{13}$. Os dois casos em análise tratam de políticas e ações governamentais ainda em curso, isto é, tanto no PTSF quanto na UHBM as obras ainda estão em andamento, e os projetos ainda não foram concluídos. Nesse sentido, ainda é cedo para estabelecermos quaisquer julgamentos sobre o efeito da inclusão e participação de atores sociais e políticos sobre os resultados dessas políticas públicas. No entanto, é possível analisarmos de que forma a existência e a operação de mecanismos de participação social e de interação com agentes políticos afetam os processos de implementação. Em outras palavras, a

\footnotetext{
${ }^{13}$ Isso significa que a análise dos efeitos da variação da inclusão política circunscreve-se aos processos contemporâneos de implementação dessas políticas. Assim, possíveis mudanças que tenham ocorrido em momentos anteriores escapam do escopo da presente análise. Por exemplo, as revisões ocorridas no caso do projeto de Belo Monte no final dos anos 1990, envolvendo a redução drástica da área alagada e a introdução da tecnologia de fio d'água para geração de energia, não são consideradas aqui, por não poderem ser atribuídas às características de gestão do projeto no período recente (pós-2007).
} 
comparação entre a implementação do PTSF e da UHBM nos permite avaliar e qualificar os argumentos da literatura sobre os efeitos da ampliação da inclusão e participação de atores diversos nas políticas de desenvolvimento.

Como será discutido nesta seção, as trajetórias de implementação e as capacidades de articulação de interesses e processamento de conflitos são marcadamente diferentes nos dois casos estudados. Como o PTSF e a UHBM compartilham características comuns em termos de seus objetivos, tipos de intervenção, existência de conflito e dos arranjos e atores burocráticos envolvidos, argumenta-se as diferenças em termos de inclusão e participação política contribuem muito para explicar as distinções observadas na capacidade de processamento de conflitos e incorporação de inovações.

No caso do PTSF, inicialmente, o processo de implementação foi marcado por conflitos e tentativas de veto e obstacularização do projeto. Entidades da sociedade civil representando os grupos populacionais e os estados afetados se articularam em torno da formação de um Fórum de Defesa Permanente do São Francisco, ainda em 2001 (BRASIL, 2011). Nesse momento, as audiências públicas ligadas ao processo de licenciamento ambiental do projeto foram iniciadas, porém, sujeitando-se a interrupções por meio de ações judiciais (ABERS; KECK, 2013). Nessa fase, foram emitidas onze liminares contra a obra, com destaque para aquelas impetradas junto ao Supremo Tribunal Federal (STF) pelos Ministérios Públicos dos Estados da Bahia e de Minas Gerais e pelo Ministério Público Federal ${ }^{14}$. Contudo, essa fase de disputa e judicialização do processo se encerra em dezembro de 2006, quando o STF derrubou todas as liminares contrárias à obra de transposição e, em 2007, o Ibama expediu a Licença de Instalação, já definindo condicionantes para a posterior Licença de Operação. Tal momento resultou da construção da viabilidade política do projeto, a qual se deveu ao processamento dos conflitos e tensões por meio de canais institucionais existentes para expressão de demandas, negociação e tomada de decisão sobre o projeto.

A "pacificação" dos conflitos e a conciliação de interesses divergentes se construiu, no caso do PTSF, a partir de diversas interações das burocracias implementadoras com agentes políticos (governadores e parlamentares no Congresso Nacional) e da participação de atores organizados da sociedade civil em fóruns institucionais (CBHSF e CNRH). Essas interações criaram oportunidades para o debate entre diferentes atores (governamentais e

\footnotetext{
${ }^{14}$ Além disso, destaca-se a greve de fome do Frei Luiz Flávio Cappio em oposição ao projeto.
} 
não governamentais) e para a pactuação de acordos, os quais promoveram aperfeiçoamentos e a incorporação de novas demandas não contempladas no projeto inicial. Tal como relatam Loureiro, Teixeira e Ferreira (2013, p.12), como resultado, o projeto chegou a ter seu próprio escopo revisto:

(...) ele focalizava, em seu desenho inicial, apenas a transposição de águas para os estados mais ao norte de sua nascente. Em decorrência de numerosos conflitos e negociações em torno de seu desenho, o projeto passou a ter seu objetivo ampliado, incluindo também a revitalização das águas do rio. Hoje ele se denomina Projeto de Integração do Rio São Francisco (PISF).

O CBHSF, criado em $2001^{15}$, constituiu-se um fórum para articulação dos opositores ao projeto de transposição, pois a maior parte de seus membros defendia a revitalização do rio São Francisco, uma vez que eles questionavam a eficácia do desvio das águas para a solução do problema de desenvolvimento no semiárido e chamavam atenção para as situações dramáticas de acesso a recursos hídricos ao longo das margens do próprio rio (ABERS; KECK, 2013). Ainda em 2004, com base na realização de uma série de consultas públicas, o CBHSF emitiu deliberação declarando a prioridade da utilização da água para usos internos à bacia e, apenas em segundo lugar, para usos externos, desde que a destinação da água ocorresse somente para o consumo humano e animal. Essa decisão tornaria inviável qualquer emprego da vazão da transposição em atividades econômicas, o que levou os representantes do Governo Federal no CBHSF a entrarem com pedido de vista contra a decisão e remetendo a deliberação sobre o uso das águas para instância superior, no caso, o Conselho Nacional de Recursos Hídricos (CNRH). Tal conselho, em função de sua composição predominantemente governamental, acabou revendo a deliberação do CBHSF, a qual impunha sérias restrições à viabilização do projeto, aprovando a outorga em $2005^{16}$.

\footnotetext{
${ }^{15}$ Abers e Keck (2013) analisam em detalhe o processo de construção institucional do Comitê de Bacia Hidrográfica do Rio São Francisco, em perspectiva histórica e comparada com outros casos semelhantes no Brasil.

${ }^{16}$ Esse momento foi interpretado por vários representantes das organizações da sociedade civil como um "atropelamento" por parte do governo, no sentido da desmoralização das decisões dos comitês de bacias hidrográficas. Em reação, algumas organizações da sociedade civil denunciaram a "destruição" do sistema nacional de gestão participativa dos recursos hídricos passaram a boicotar as reuniões desses comitês (ABERS; KECK, 2013).
} 
No entanto, nesse processo de negociação, alguns novos elementos acabaram sendo introduzidos. A atuação do CBHSF foi decisiva para evitar que a água fosse utilizada em escala comercial para a irrigação em empreendimentos agrícolas de grande porte, como ocorreu com a Construção da Hidrelétrica e formação do lago de Sobradinho, também no Rio São Francisco, durante o Regime Militar ${ }^{17}$. Além disso, criou-se espaço para a reformulação do projeto inicial, focado apenas na transposição, adicionando-se um componente de revitalização da bacia hidrográfica do Rio São Francisco. Segundo, Loureiro, Teixeira e Ferreira (2013, p.17), o presidente do CBHSF afirmou:

O CBHSF exerceu o papel de linha de frente na luta contra a Transposição nos moldes megalômanos concebidos desde os governos militares e acatados pelas administrações Fernando Henrique e Lula da Silva. Resistiu ao projeto tanto no plano técnico e intelectual, promovendo os debates mais importantes sobre o assunto, como no plano da mobilização política, institucional e popular (...) O projeto de revitalização foi um ganho dos que resistiram à Transposição. A maior parte dos recursos destinados aos diferentes projetos e programas de revitalização do Rio São Francisco está sendo aplicada nos estados de Minas Gerais e Bahia, os que lideraram o processo de resistência à Transposição.

Em paralelo, no Congresso Nacional, os parlamentares se dividiam em blocos contrários e favoráveis ao PTSF. Parlamentares e lideranças políticas de estado, como Pernambuco, Rio Grande do Norte, Ceará e Paraíba, eram a favor do projeto para o combate dos efeitos da seca no semiárido. Já os políticos de Bahia, Minas Gerais, Sergipe e Alagoas se sentiam prejudicados com a potencial perda de recursos hídricos com a transposição e de recursos orçamentários para investimentos nos seus interiores. Assim, a introdução do componente de "revitalização", o qual envolvia a realização de investimentos ao longo das margens do rio, para além dos investimentos já previstos como condicionantes do processo de licenciamento ambiental, beneficiando os

\footnotetext{
${ }^{17}$ Em 2005, o CNRH decidiu aprovar nota técnica da Agência Nacional de Águas que tratava da sustentabilidade hídrica da utilização de águas para o Projeto de Transposição. Nela se definia que as águas deveriam ser utilizadas prioritariamente para o consumo humano, podendo ser empregadas para outros usos nas ocasiões em que a represa de Sobradinho verter (LOUREIRO; TEIXEIRA; FERREIRA, 2013).
} 
estados contrários ao projeto, galvanizou o apoio dos opositores ao projeto, tanto aqueles que apontavam os riscos ambientais e sociais quanto aqueles que temiam perda de recursos e investimentos em seus estados. Tal como informado por um representante do Ministério da Integração Nacional, os investimentos previstos para o componente de revitalização chegaram a somar o mesmo volume de recursos dedicados às obras de transposição ${ }^{18}$. Assim, no caso do PTSF, a existência de espaços de interação entre atores estatais, políticos e societários permitiu a interlocução e o debate, culminando na identificação de novas estratégias de legitimação e em aperfeiçoamentos para a política.

Diferentemente, no caso da UHBM, os conflitos iniciais têm persistido ao longo de todo o processo de implementação, acirrando tensões entre atores estatais e sociais e corroendo gradualmente a legitimidade do projeto. Essas tensões têm se manifestado em intensa judicialização, envolvendo desde interrupções no processo de licenciamento da usina, motivadas por ações civis públicas impetradas pelo Ministério Público, a outros processos judiciais no Brasil e internacionalmente relativos à legalidade do projeto, como o questionamento da Comissão de Direitos Humanos da Organização dos Estados Americanos (OEA), somando-se, ainda, às paralisações das obras devido a greves de trabalhadores, manifestações e ações de protesto dos grupos afetados (HOCHSTETLER. 2011). As dificuldades de resolução dos conflitos que permeiam o projeto repercutem em dificuldades de execução das ações e concorrem para explicar a baixa aceitabilidade da usina junto aos grupos sociais envolvidos (ONGs, grupos indígenas e movimentos sociais locais e internacionais) e o ceticismo dos mesmos em relação aos compromissos firmados pelos órgãos governamentais relativos às compensações pelo impacto socioambiental e aos planos de desenvolvimento para a região ${ }^{19}$ (FEARNSIDE; LAURANCE, 2012; ABERS; OLIVEIRA; PEREIRA, 2014).

A debilidade dos processos e mecanismos de interação com agentes políticos e atores sociais reduziu as oportunidades de debate, interlocução e formulação de soluções alternativas aos problemas identificados. A

\footnotetext{
${ }^{18}$ Isso porque o componente de investimento em obras de revitalização excedia em muito o volume de investimentos e obras já previstas como "programas básicos ambientais", exigidos pelo Ibama como condicionantes do licenciamento socioambiental (BRASIL, 2011).

19 No total, previu-se um volume de $\mathrm{R} \$ 1.87$ bilhões em compensação social e ambiental (HOCHSTETLER, 2011).
} 
velocidade com que o projeto tramitou no Congresso Nacional não permitiu que os parlamentares interessados se organizassem e provocassem discussões e negociações em torno do mesmo. Além disso, no caso da UHBM, não existem espaços participativos com caráter decisório e natureza permanente e institucionalizada, como a CBHSF ou o CNRH. O Conselho Nacional de Política Energética (CNPE) conta apenas com dois membros não governamentais (em meio a doze representantes governamentais) indicados pelo próprio governo, sendo um representante da sociedade civil especialista em matéria de energia e um representante da universidade brasileira. Assim, apesar de possuir caráter decisório estratégico no arranjo decisório da UHBM, ele não se constitui como esfera de inclusão política e participação social. Dessa forma, o único mecanismo de interação com atores sociais utilizado foram as audiências públicas, exigidas pelo processo de licenciamento ambiental. Essas, por sua vez, tiveram sua realização criticada por vários atores sociais e pelo Ministério Público Federal como não tendo sido promovidas de forma adequada (em termos de seu escopo, momento de realização, representatividade do público participante e ausência de sistematização e devolutiva). Assim, não viabilizaram a manifestação e o registro das demandas sociais dos grupos atingidos pelo projeto (FONSECA, 2013).

Ainda que essas falhas na realização das audiências tivessem sido superadas, observa-se que a abertura à participação e inclusão de uma pluralidade de atores no processo de implementação da UHBM se dá em uma etapa relativamente descolada do núcleo decisório da política no setor elétrico. Isto é, dificilmente debates e manifestações colhidas nessas audiências públicas, vinculadas ao processo de licenciamento ambiental, repercutiriam em revisões no projeto por parte das burocracias do setor elétrico, conhecidas por um padrão de atuação insulada e com baixa participação da sociedade (PEREIRA, 2013).

Assim, mesmo que interesses conflitantes em torno do projeto venham sendo explicitados, seja na mídia ou no debate público, a incipiência de mecanismos efetivos de inclusão e participação política prejudica a capacidade de processamento de conflitos, conciliação de interesses e revisões de acomodação no desenho e nas estratégias de implementação do projeto. A obra da usina tem seguido adiante, porém, sem que um consenso mínimo em torno da mesma tenha sido construído. Como consequência, apesar da introdução de revisões importantes nos 1990 - como a adoção de tecnologia de fio d'água, a qual permitiu a produção de grande quantidade 
de energia com área de alagamento relativamente pequena em comparação com os projetos de hidroelétricas do passado, como Tucuruí e Balbina, por exemplo $^{20}$ - não se verificam aperfeiçoamentos ou revisões que tenham emergido desde a retomada da implementação do projeto, em 2005, no sentido da conciliação de interesse dos atores que disputam o projeto ${ }^{21}$.

Em suma, a comparação entre os dois casos sugere que a existência e operação de processos de inclusão de atores sociais e políticos - os quais permitam não só a explicitação de interesses divergentes como também debates, negociações e a construção de acordos possíveis - permite a transformação dos conflitos em torno das políticas de desenvolvimento em aprimoramentos e revisões das ações e estratégias governamentais. No caso do PTSF, as tensões se desdobraram em blocos de parlamentares favoráveis e contrários ao projeto, elevando o debate sobre o tema. Além disso, o Comitê de Bacia Hidrográfica do Rio São Francisco (CBHSF) proporcionou espaço para explicitação de divergências e articulação dos interesses contrários ao projeto de transposição. Essa arena participativa promoveu a mobilização política, institucional e popular e serviu de lócus para formulação de propostas alternativas, resultando na repactuação do escopo inicial do projeto e na incorporação dos objetivos de revitalização do Rio São Francisco, beneficiando também as regiões que virão a ser prejudicadas com a transposição das águas (LOUREIRO; TEIXEIRA; FERREIRA, 2013). ${ }^{22}$

\footnotetext{
${ }^{20}$ Abers, Oliveira e Pereira (2014) descrevem tais revisões, introduzidas no desenho do projeto nos anos 1990, como frutos de decisões tecnocráticas, e não de negociações diretas com atores da sociedade civil. Decisões tomadas pela burocracia federal como forma de antecipar as repercussões negativas (nacionais e internacionais) que poderiam ocorrer com a retomada do projeto no início dos anos 2000.

${ }^{21}$ Há que se destacar, no entanto, que no período recente foram criados novos mecanismos de participação social para a discussão e gestão de ações voltadas para a mitigação de impactos e compensação pelos danos socioambientais, como no caso do Plano de Desenvolvimento Regional Sustentável do Xingu, o qual prevê aproximadamente $\mathrm{R} \$ 500$ milhões em investimentos. As iniciativas de promoção da participação social mais recentes têm sido promovidas por esforços da Secretaria Geral da Presidência da República, como o comitê-gestor, com participação de representantes governamentais e da sociedade civil, que monitora a implementação do Plano, além da Casa de Governo, na cidade de Altamira. Por serem iniciativas relativamente recentes, ainda é difícil avaliar os efeitos que terão sobre o processo de implementação da Usina.

${ }^{22}$ Apesar desses avanços, alguns estudos têm demonstrado os impactos negativos da obra para as comunidades e povos tradicionais afetados. Brasil (2011) mapeou e analisou as repercussões do projeto para uma comunidade quilombola no interior de Pernambuco, indicando fortes interferências nas condições de vida e subsistência dessas populações.
} 
Caso diverso se observa na UHBM, na qual os distintos atores envolvidos não tiveram as mesmas oportunidades de influência no processo. Por um lado, o Congresso não demonstrou a devida atenção com a promoção de debates sobre o tema e não viabilizou a inclusão dos interesses das populações diretamente afetadas (oitivas). Por outro lado, as audiências públicas realizadas foram criticadas pela forma como foram promovidas e por não influírem no núcleo decisório do setor elétrico. Ao não serem tratadas e contempladas, as demandas dos opositores ao projeto se direcionaram ao Poder Judiciário, por via da atuação do Ministério Público. Isso tem promovido intensa judicialização do processo de implementação da Usina. Assim, além de não promover repactuações e inovações, a ausência de inclusão política, nesse caso, tem repercutido também em obstáculos à execução do projeto - por exemplo, somente entre 2008 e 2009, ocorreram três interrupções no processo de licenciamento da Usina (PEREIRA, 2013).

\section{Considerações finais}

Ao longo da última década, observa-se a retomada de um ativismo estatal na implementação de políticas públicas de caráter desenvolvimentista. No entanto, a condução de tais políticas, características de nosso passado autoritário, passa a ocorrer de maneira diferente a partir do ambiente político-institucional instaurado pela Constituição de 1988, o qual impõe requisitos de transparência e prestação de contas, participação e controle por parte da sociedade civil e dos poderes Legislativo e Judiciário. O presente artigo se dedicou a investigar os efeitos dessa ampliação da inclusão política, estimulada pelo atual ambiente político-institucional sobre a implementação de duas políticas de desenvolvimento: o Projeto de Transposição do Rio São Francisco e a construção da Usina Hidrelétrica de Belo Monte.

A literatura sobre o tema tem apontado para duas possíveis direções para a interpretação dessa relação entre ampliação da participação e implementação. Enquanto alguns autores chamam atenção para potenciais tensões - ineficiência, impasses e obstáculos -, outra corrente argumenta pelas potenciais sinergias - responsividade, qualidade das decisões e legitimidade -, resultantes de uma maior inclusão de atores políticos e sociais na implementação de políticas de desenvolvimento.

A análise comparativa dos casos sugere uma interpretação mais nuançada. Por um lado, os casos estudados demonstram que a introdução 
de requisitos de inclusão e participação política, pós-1988, ainda que não tenha ocorrido de forma plena e extensiva, acrescentou complexidades ao processo de implementação de políticas de desenvolvimento. Pois, se outrora, tais políticas poderiam ser concebidas e implementadas a partir de fóruns decisórios restritos e da concentração de poder em poucos atores burocráticos ${ }^{23}$; atualmente, observa-se que a implementação de políticas de desenvolvimento se dá a partir de arranjos institucionais, envolvendo não só atores burocráticos diversos, mas, também, atores políticos (partidos políticos, parlamentares, governadores e prefeitos) e atores sociais (associações, sindicatos, movimentos sociais, ONGs, etc.) em processos de consulta, negociação e decisão compartilhada. A complexidade adicionada por esses arranjos necessariamente reduz a eficiência potencial dos processos de implementação, uma vez que introduz novas camadas de processos, além de novos atores com novas atribuições e poderes de moderação ou veto.

Ademais, a análise comparativa dos casos indicou que, para além dos potenciais impasses e obstáculos advindos dessa complexidade, a ampliação da inclusão e envolvimento de atores sociais e políticos, quando ocorre adequadamente, tem papel importante na promoção de inovações ao longo da implementação dos programas. Isto é, arranjos institucionais capazes de incluir múltiplos atores e de processar conflitos entre eles, como no caso do PTSF, tendem a induzir revisões, mudanças e a introdução de novidades (novos objetivos, processos e instrumentos) não previstas no desenho original das políticas. A ausência (ou má operação) desses mecanismos, como no caso da UHBM, tende a reforçar e reproduzir conflitos já existentes, acrescentando obstáculos ao processo de implementação, pois as divergências e tensões tenderão a ser canalizadas por outras vias, como a da judicialização ou a da mobilização social e da contestação violenta.

A comparação entre os dois casos não nos permite generalizar suas conclusões para o conjunto das políticas governamentais. Contudo, dada

\footnotetext{
${ }^{23}$ Por exemplo, podemos citar a implantação da Usina Hidrelétrica de Tucuruí, nos anos 1970. A partir dos estudos iniciais sobre o projeto em 1973, em menos de um ano, o governo federal já havia iniciado as obras de construção da usina, concluindo-a em um período de 10 anos. Os estudos ambientais só foram elaborados após o início das obras, em um período em que a legislação ambiental era bem menos rigorosa. Já no caso de Belo Monte, o início das obras se deu em 2011, seis anos após a sua aprovação pelo Congresso Nacional e o início do processo de licenciamento ambiental.
} 
a relevância e o caráter emblemático dos mesmos, como exemplos desse ativismo estatal contemporâneo, acredita-se que esses achados contribuem para refinarmos e atualizarmos nossas interpretações sobre a relação entre burocracia e inclusão política na produção do desenvolvimento social e econômico no Brasil.

\section{Referências}

ABERS, Rebecca; OLIVEIRA, Marilia; PEREIRA, Ana Karine.

(2014). Development, participation, and the asymmetric state: big projects and local communities in the Brazilian Amazon. Artigo apresentado no encontro da American Political Science Association (APSA). Washington - DC, 28 a 31 de agosto.

ABERS, Rebecca; KECK, Margaret.

(2013). Practical Authority: Agency and Institutional Change in Brazilian Water Politics. Nova Iorque: Oxford University Press.

BARDACH, Eugene.

(1977). The Implementation Game. Cambridge, MIT Press.

BRASIL, Daniel.

(2011). 0 mar virou sertão: a transposição do Rio São Francisco e a comunidade quilombola de Santana. Dissertação de Mestrado apresentada ao Programa de Pós-graduação do Centro de Desenvolvimento Sustentável, da Universidade de Brasília.

CARDOSO, Fernando Henrique.

(1975). Autoritarismo e democratização. Rio de Janeiro: Paz e Terra.

EVANS, Peter.

(2011).The capability enhancing developmental state: concepts and national trajectories. Texto para Discussão, n. 63. Centro de Estudos sobre Desigualdade e Desenvolvimento (CEDE). Disponivel em: http://www.proac.uff. $\mathrm{br} / \mathrm{cede} / \mathrm{sites} /$ default/files/TD63.pdf. Acesso em 15 de dezembro de 2014.
EVANS, Peter.

(1995). Embedded Autonomy - States and Industrial Transformation. New Jersey, Princeton Press.

EVANS, Peter; HUBER, Evelyne; STEPHENS, John.

(2013). The political foundations of state effectiveness, forthcoming. In: Miguel Centeno, Deborah Yashar e Atul Kholi (Orgs.); State building in the developing world.

FEARNSIDE, Phillip; LAURANCE, William.

(2012). Infraestrutura na Amazônia: as lições dos planos plurianuais. Caderno CRH, v.25, n.64, p.87-98.

FONSECA, Igor; RESENDE, Raimer; OLIVEIRA, Marília; PEREIRA, Ana Karine.

(2013). Audiências Públicas: fatores que influenciam seu potencial de efetividade no âmbito do Poder Executivo Federal. Revista do Serviço Público, 64 (1), p.7-29.

GOMIDE, Alexandre; PIRES, Roberto

(2014). Capacidades Estatais e Democracia: arranjos institucionais de políticas públicas. Brasília: IPEA.

HOCHSTETLER, Kathryn.

(2011). The politics of environmental licensing: energy projects of the past and future in Brazil. Studies in Comparative International Development v.46, p.349-371.

HOCHSTETLER, Kathryn; KECK, Margaret. (2007). Greening Brazil: Environmental Activism in State and Society. Durham \& London: Duke University Press. 
JOHNSON, Chalmers.

(1982). Japan: who governs - the rise of the developmental state. New York, W.W. Norton \& Company.

LEFTWICH, Adrian.

(1998). Forms of democratic developmental States. Democratic Pratices and development capacity. In: Mak Robinson; Gordon White (Eds.); The democratic developmental State. Political and Institutional Design. 0xford: Oxford University Press. p. 52-83.

LIJPHART, Arend.

(1999). Patterns of democracy. Government forms and performance in thirty-six democracies. Yale University Press.

LOUREIRO, Maria Rita; TEIXEIRA, Marco Antonio; FERREIRA, Alberto.

(2013). Democracia e Desenvolvimento no Brasil contemporâneo: conflitos e articulação de interesses no Projeto São Francisco. Texto para Discussão n¹883. Instituto de Pesquisa Econômica Aplicada (Ipea). Brasília.

LOUREIRO, Maria Rita; MACARI0, Vinícius; GUERRA, Pedro.

(2013). Democracia, arenas decisórias e políticas públicas: o Programa Minha Casa Minha Vida. Rio de Janeiro: Ipea. (Texto para Discussão, n. 1.886).

MARTINS, Luciano.

(1985). Estado Capitalista e Burocracia no Brasil Pós-64. Paz e Terra.

MATTHEWS, Felicity.

(2012). Governance and state capacity. In: David Levi-Faur (Org.); The Oxford Handbook of Governance. Oxford University Press. p.281293.

MPF - MINISTÉRIO PÚBLICO FEDERAL. (2009). Recomendação n5.

NESHKOVA, Milena; GU0, Hai.

(2011). Public Participation and Organizational Performance: Evidence from State Agencies. Journal of Public Administration Research and Theory. First published online July
20, 2011 doi:10.1093/jopart/mur038http://jpart.oxfordjournals.org/content/ early/2011/07/20/jopart.mur038. full. pdf+html.

PEREIRA, Ana Karine.

(2013). Desenvolvimentismo, Conflito e Conciliação de Interesses na Política de Construção de Hidrelétricas na Amazônia brasileira. Texto para Discussão nº1884. Instituto de Pesquisa Econômica Aplicada (Ipea). Brasília.

PIRES, Roberto (Org.).

(2011).EfetividadedasInstituições Participativas no Brasil: Estratégias de Avaliação. Brasília: Ipea.

PIRES, Roberto; TOMAS, Maria Carolina.

(2007). Instituições participativas e gestão municipal no Nordeste: uma análise dos efeitos da participação sobre as práticas de governo. In: Leonardo Avritzer (Org.); A participação social no Nordeste. Belo Horizonte: Editora da UFMG.

PIRES, Roberto; VAZ, Alexander.

(2010). Participação faz diferença? Uma avaliação das características e efeitos da institucionalização da participação nos municípios brasileiros. In: Leonardo Avritzer (Org.); A dinâmica da participação local no Brasil. São Paulo: Cortez.

PRESSMAN, Jeffrey; WILDAVSKY, Aaron.

(1973). Implementation. Berkeley, University of California Press.

SABEL, Charles.

(2004). Beyond Principal-Agent Governance: Experimentalist Organizations, Learning and Accountability. In: ENGELEN, E.; H0, M. (eds.), De Staat van de Democratie. Democratie voorbij de Staat. WRR Verkenning 3. Amsterdam: Amsterdam Press.

SABEL, Charles; ZEITLIN, Jonathan.

(2012). Experimentalist governance. In: David Levi-Faur (Ed.); The Oxford Handbook of Governance. Oxford University Press. p.169186. 
SÁ e SILVA, Fábio; LOPEZ, Felix; PIRES, Roberto.

(2010). Introdução: A Democracia no Desenvolvimento e o Desenvolvimento da Democracia". In: Fábio Sá e Silva; Felix Lopez; Roberto Pires (Orgs.); Estado, instituições e democracia: democracia. Brasília: IPEA, v. 2, p. 17-46.

SEN, Amartya.

(2000). Desenvolvimento Como Liberdade. São Paulo: Companhia das Letras.

SORENSEN, Eva.

(2012) . Governance and innovation in the public sector. In: David Levi-Faur (0rg.); The Oxford Handbook of Governance. Oxford University Press. p.215-227.

STARK, David; BRUSTZ, Lazlo.

(1998). Enabling constraints: fontes institucionais de coerência nas políticas públicas no pós-socialismo. Revista Brasileira de Ciências Sociais, Vol. 13, n.36, p.13-39.
ZAMBONI, Yves.

(2007). Participatory budgeting and local governance: an evidence-based evaluation of participatory budgeting experiences in Brazil. Working paper, May 28. Disponível em: http://siteresources.worldbank.org/ INTRANETSOCIALDEVELOPMENT/Resources/ Zamboni.pdf. Acesso em março de 2010.

WADE, Robert.

(1990). Governing the market: economic theory and the role of government in East Asian industrialization. Princeton: Princeton University Press.

\section{Recebido em}

janeiro de 2014

\section{Aprovado em}

fevereiro de 2015 